JQCJC VOLUME 8 ISSUE 2 (WINTER 2020)

\title{
SOCIAL EXCHANGE AND THE FORMATION OF PRISON VISITATION COMMUNITIES
}

\author{
Adam Trahan ${ }^{1}$ \\ University of North Texas \\ Douglas Evans \\ Fairleigh Dickinson University
}

\begin{abstract}
Family members and significant others of incarcerated individuals suffer when their loved ones are incarcerated. The loss of a parent, sibling, child, spouse, or partner to incarceration can be painful. If they wish to stay physically connected to an incarcerated individual, visitation is their only recourse. Visiting a prison can be costly in terms of the amount of time it takes to travel to the facility, the total expenses incurred during travel, and the socio-emotional effects of limited contact. On top of these costs, visitation can be an intricate process to navigate due to the multitude of facility rules and the difficulty of preparing for them. Overlooking even one rule can result in denial of entry, ending a visitation before it even starts. Inexperienced visitors are at a particular disadvantage because of their lack of familiarity with the formal and informal rules of a secure facility. The strictness of facility policies and staff charged with enforcing them places visitors with experience in a position to offer valued resources to new visitors. Resources can be socioemotional, informational, material, or economic benefits that help visitors navigate a successful visitation. This study uses interviews with relatives and significant others of currently or formerly incarcerated individuals to explore the social exchanges that occur between visitors to prisons.
\end{abstract}

Keywords: Social exchange theory, prison visitation, inmates' families, thematic content Analysis

\section{INTRODUCTION}

Incarceration has devastating consequences for people sentenced to jails and prisons. Spending time in a secure facility strips individuals of their citizenship and social life, prevents them from working, building romantic relationships, raising children, maintaining households, and contributing to community life. In addition to the direct consequences of incarceration, there are ramifications for family members and loved ones of those who are incarcerated. They are left behind to deal with the financial consequences of imprisonment, as well as the loss of emotional and familial support. The current study uses qualitative interviews with persons who visit

\footnotetext{
${ }^{1}$ Correspondence concerning this article should be addressed to Adam Trahan, Department of Criminal Justice, University of North Texas, 1155 Union Circle \#305130, Denton, Texas, 76203-5017. Phone: (940) 369-8860.

Email: Adam.Trahan@unt.edu. This study has IRB approval from UNT and Mercy College.
} 


\section{TRAHAN \& EVANS}

incarcerated loved ones to explore the social exchanges that they engage in with one another during visitation. Social exchanges provide the foundation by which individual visitors become part of a larger group that regularly visits people held in secure facilities. Using social exchange as the theoretical framework extends research on family visitation of loved ones held in secure confinement (Arditti, 2003; Arditti, 2005; Arditti, 2012; Naser \& Visher, 2006; Christian, 2005; Duwe \& Clark, 2013).

Given the approximately 2.3 million people currently in jails and prisons in the US (Wagner \& Rabuy, 2017), incarceration potentially affects tens of millions of family members, significant others, and friends on the outside in myriad ways. They endure unique difficulties, many times without support from significant others or governmental resources. Secondary stigma resulting from the incarceration of their loved ones could damage their reputation and reduce their social networks. Many of these individuals find kinship with others who have an incarcerated loved one. Visitors to jails and prisons often cultivate informal relationships with other similarly situated others during the prison visitation experience. They offer support, understanding, and information through social exchanges, which help adapt to the burdens associated with prison visitation and contribute to the formation of relationships.

Visitation facilitates maintenance of a bond with someone who is incarcerated, but there are negative effects to consider. Visiting a prison has emotional consequences in addition to financial and time costs, all of which expand with the distance between family members and the facility in which their loved ones are incarcerated. Maintaining contact during incarceration through phone or visitation costs hundreds per month to loved ones on the outside (Christian, Mellow, \& Thomas, 2006). More than half of all visitors to prisons live over 100 miles from the prison where their loved one is incarcerated (Klopton \& East, 2008). Some social agencies have not allowed children to visit prisons so that they avoid the negative environment, and some incarcerated parents worry about the shame their children could feel from seeing their parents locked up (Sack \& Seidler, 1978). Despite these concerns, the majority of children report no adverse effects from visitation (Johnston, 1995).

Qualitative analyses indicate that the hurdles that many facility rules potentially pose, concomitant with a perceived lack of clarity and assistance from correctional officers, creates an environment in which novice visitors seek to benefit from social exchanges - in the form of information, as well as material and socioemotional benefits - with visitors who have more experience navigating formal and informal facility rules. Learning the written and tacit rules of visitation brings together individuals who were previously strangers, bound only by their common goal of visitation, to overcome institutional barriers to maintaining a relationship with an incarcerated loved one.

\section{LITERATURE}

\section{Visitation in Prison}

Visitation between inmates and family members can be challenging, but it is necessary to maintain some semblance of familial bond and unity. The majority of contact between inmates and their loved ones occurs in a single, large room designated for meetings between preapproved visitors and individuals incarcerated in a secure facility. This prison visitation room becomes the singular space for familial interactions with an incarcerated member (Arditti, 2012). Travel time and costs pose recurring barriers to visitations. Visiting an incarcerated loved one can take hours 


\section{JQCJC VOLUME 8 ISSUE 2 (WINTER 2020)}

by car, plane, public transportation, or a combination of transportation methods. Many family members live more than 100 miles from the facilities in which their loved ones are incarcerated (Schirmer, Nellis, \& Mauer, 2009; Clark \& Duwe, 2017). Travel can also be expensive, whether the expenses incur because of gas, bus or train tickets, cab fare, or flight costs. People who visited a loved one in a medium-security prison in Kentucky spent an average of $\$ 250$ per month (Tewksbury \& DeMichelle, 2005). Travel time and expenses increase with the distance between visitors' residences and secure facilities.

Various factors discourage visitations and make it difficult for visitors to see their incarcerated loved ones. Secure facilities have rules surrounding visits to ensure security and safety of the facility, but family members, significant others, and friends have to navigate the sometimes complicated process of learning a facility's rules and procedures to make the most of their brief visits. Many rules are consistent across facilities, but each prison has its unique set of written guidelines and unpublicized regulations that can be especially burdensome to the loved ones of an inmate who is transferred to multiple facilities. New York State, one of the current study sites, posts visiting hours, the maximum number of visitors per day/visit, and facility addresses online. The state Department of Corrections and Community Supervision (DOCCS) website lists visitation guidelines, including rules about searches of visitors, but provides no information about money visitors can bring for snack machines located in some facility visiting areas. The other primary site in the current study is Texas. The Texas Department of Criminal Justice also posts basic information on rules and procedures for visitation online, along with a series of videos showing what visitors can expect. If visitors do not comply with the rules, staff can deny them entry at any time leading up to a visit. Potential visitors may be further dissuaded from prison visits because of the secondary prisonization that accompanies visitation.

Prisonization refers to the imposition of a less intense version of security rules, surveillance, and confinement on those who visit inmates (Comfort, 2003).

The entire process can be time-consuming. Before undergoing security procedures, facility staff and policies could require visitors to wait up to an hour or more before entering the facility. Following invasive security checks, they walk through multiple locked metal gates and doors before arriving at the visitation room (Arditti, 2003). The whole experience of visitation can last a full day, and the majority of that time is spent on travel and traversing the security process. The visitation is secondary to facility security in terms of time and importance. Actual visits are often limited, particularly in terms of duration and physical contact. Family members visiting someone inside a secure facility have expressed concerns about the lack of contact they are allowed to have with inmates, the minimal privacy they are afforded, and the short amount of time they are allowed, which can be as brief as 20 minutes (Arditti, 2003). Overall, a visit to a jail or prison can be a physically draining, tiring, and stressful experience (Christian, 2005).

Visiting a loved one in prison can be difficult, but it can also have positive benefits for all parties. It is crucial to maintaining relationships between a parent inside and their child on the outside. However, it can compound a family's financial deficits and could exacerbate conflicts between inmates and their loved ones (Arditti, 2005). Studies have shown that visitation may have positive effects on behavior both during and following incarceration. Inmates who receive visits from family members during incarceration are less likely to commit acts of misconduct in the facility (Cochran, 2012). A subsequent study that explored the relationship between visitations and behavior found that inmate infractions actually decrease leading up to visitation and increase shortly after the visit, then gradually return to average levels (Siennick, Mears, \& Bales, 2013). Physical contact during incarceration is important for families because familial 


\section{TRAHAN \& EVANS}

relationships can improve with regular visitation and contact. This is especially true of relationships between the incarcerated and their child or children (LaVigne et al., 2005).

Research has explored associations between visitation and post-release outcomes, though most focuses on attainment or avoidance of a negative outcome. Visitation appears to have a mostly positive effect on recidivism. Following their release, inmates who received regular visits one year prior to their release had a one-third lower likelihood of post-release recidivism (Bales $\&$ Mears, 2008). A study that used propensity score matching to more extensively explore this relationship found that visitation reduced recidivism for violent, property, and drug offenses. Visits from spouses or significant others were associated with the largest decreases in recidivism (Mears et al., 2012). Although visits from family members, in-laws, and mentors are associated with a 13 percent decrease in felony reconvictions and a 25 percent drop in revocations for a technical violation, visits from ex-spouses are associated with an increase in post-release recidivism (Duwe \& Clark, 2013). Political and social support or opposition toward visitation programs depends in part on their ability to reduce recidivism.

Some states have implemented alternatives to in-person visitations to reduce safety risks and costs associated with supervising visits. Fifteen states have at least some facilities that use video visitation for communication with incarcerated family members. The benefits are that it saves travel time and costs for visiting family members, but it can be expensive for inmates. Nearly half of inmates surveyed in facilities that offer video visitation were unable to afford the $\$ 12.95$ fee for 30 minutes of video communication (Digard et al., 2016). Visitation through virtual contact facilitates communication but also imposes a physical distance between family members viewing one another on a screen.

Visiting someone in a secure facility can be daunting, especially for individuals who are visiting an incarcerated loved one for the first time. Many policies are in place to protect staff, inmates, and visitors and also to provide good behavior incentives for inmates who wish to receive visitors. Visits require prior approval and background checks, meaning that visitors could be denied entry if they have a prior record; certain codes of dress and behavior are expected of visitors, and visitors must endure extensive searches to prevent contraband from entering the facility (Boudin, Stutz, \& Littman, 2013). Some visitation guidelines are common across prisons, but each facility has its own unique set of rules and unofficial policies, which can create confusion for visitors. Other rules are not intuitive and put visitors at risk of being denied entry for at least that day. When the facility does not provide accessible information about visitation policies, other visitors may be the only available source of information.

\section{Social Exchange during Visitation}

This study sought to examine visitation experiences from the perspective of inmates' family members and intimate partners on the outside. Following initial conversations with people who have visited a loved one in prison, many visitors discussed engaging in social exchanges inside and outside of the prison.

Social exchange theory, which is less a theory than a frame of reference (Emerson, 1976), can provide a lens through which to explore the exchanges between visitors awaiting entry into prison and the relations that emerge from these exchanges. Exchange is the foundation of relationships, and all relationships involve exchanges of resources. Over time, relationships develop and evolve with continued exchanges (Emerson, 1976). A social exchange orientation can contribute to an examination of the relationship building and community formation that takes 
place among visitors through the series of transactions that occur before and during prison visitation.

Meeker (1971) posited six rules that guide exchanges, including reciprocity, rationality, altruism, group gain, status consistency, and competition. Most relevant to exchange between individuals on a prison visit are reciprocity, group gain, and altruism (i.e., benefiting others at an absolute cost to oneself). Although altruism may be involved in certain exchange relations, it is not the focus of the current study.

Social exchange creates future obligations (Blau, 1964). Exchanges are either negotiated in advance or based on an expectation of reciprocity (Molm, Whitham, \& Melamed, 2012). Informal exchanges that occur prior to or during visitation are indicative of a reciprocal nature of exchange. The norm of reciprocity ensures that recipients of benefits give back and that transactions perpetuate within the group. Reciprocated exchanges in the context of prison visitation can involve a variety of resources. Experienced visitors can offer valued resources to new visitors in the form of socioemotional, informational, material, or economic benefits (Foa \& Foa, 1980). The value of these resources depends on the subjective valuations of givers and recipients. When an individual in an exchange relationship values a particular resource, he or she is likely to seek it out. A resource that might otherwise have nominal value outside of prison (e.g., quarters) has more value in prisons because it is the only means by which visitors can access another desired resource (e.g., vending machines). After learning the value of this resource, the norm of reciprocity encourages a previously inexperienced visitor to bring excess resources in the future to share with other inexperienced or unprepared visitors. The rules of reciprocity ensure that the party that receives benefits successively returns the benefits in kind (Meeker, 1971).

When resources exchanged among visitors are socioemotional and occur informally, each exchange contributes to the formation of a tightly knit community around the interdependent series of transactions (Cropanzano \& Mitchell, 2005). The rules of exchange in communal relationships differ from the rules in two-party exchanges. Communal exchange rules emphasize the needs and available resources of each group member. As one needs, he or she takes from the group "pot" of resources. Anyone with surplus resources is encouraged to contribute the extra to the pot for dispersal among group members in need (Meeker, 1971). Reciprocity and group gain set in motion exchanges between visitors that are not one-to-one from benefactor to beneficiary, but where recipients are encouraged directly or implicitly to reciprocate benefits to the next group of inexperienced visitors (Clark \& Mills, 1979; Cropanzano \& Mitchell, 2005).

Trust is necessary for exchange relationships to take place. Individuals' beliefs about the extent and frequency of others' contributions may influence if, when, or the amount they are willing to contribute (Gachter \& Fehr, 1999). Established trust enhances cooperation between individuals because it contributes to a shared sense of community with a common goal (Buchan, Croson, \& Dawes, 2002; Sabel, 1993).

The current research explores interpersonal exchanges - of information, resources, money, and even clothing - among visitors to prisons. We expect that if a communal relationship exists among experienced visitors that help neophyte visitors navigate the process of visitation and surmount the burdens associated with visiting a loved one in prison, exchanges between them will reflect the rules of reciprocity and group gain. 


\section{DATA AND METHODS}

\section{Sample and Procedure}

Data for the current study come from a purposive sample of 35 participants. To identify participants, we contacted various support organizations for family members and intimate partners of incarcerated persons in New York, Texas, and surrounding states. We solicited participation in the study from any person who had an immediate family member or intimate partner previously or currently incarcerated. The only immediate family members we did not include in the study were children of incarcerated persons because there is a relatively welldeveloped empirical and theoretical record on the effects of incarceration on children. We were interested in the effects and experiences of other family members and intimate partners of incarcerated persons. Among the participants were 23 parents, three siblings, three intimate partners, one grandparent, and five wives of incarcerated persons. Participants were asked a host of open-ended and close-ended questions about their experiences with their loved ones' incarceration. Interviews lasted approximately one-and-a-half to two hours, on average. Each interview was audio-recorded and later transcribed.

\section{Instrument}

Prior research on children of incarcerated parents and informal conversations between the authors and family members of incarcerated persons informed the development of the interview guide. Several broad categories provided the starting point for creating questions, including family dynamics before, during, and following incarceration, psychological and emotional repercussions, visitation experiences, financial burdens, and changes since reentry. Seven research assistants piloted interview questions with respondents who had or have an incarcerated family member before finalizing the interview guide. The transcripts of interviews with the 35 participants were analyzed using a six-phase thematic content analysis model developed by Braun and Clarke (2006), as described below.

\section{Thematic Content Analysis}

The current study was designed to generate a better understanding of the social exchanges that loved ones of incarcerated persons engage in during visitation. Before analyzing the interview transcripts, we framed the analysis using four guidelines laid out in the Braun and Clarke (2006) model of thematic content analysis.

The first guideline involves whether to measure prevalence within each data item ${ }^{2}$ or across the entire data set. Measuring prevalence within data items is a way of gauging how much "space" (or time) is allocated to any given concept by the participants of the analysis without regard to how many participants discussed the concept. We chose to measure prevalence across the data set. Our interest was in identifying common characteristics of social exchange at visitation that were experienced by a relatively large number of family members and intimate partners of incarcerated persons.

2. A "data item" refers to an individual piece of data, the sum of which constitutes the data set. 


\section{JQCJC VOLUME 8 ISSUE 2 (WINTER 2020)}

The second guideline involves determining whether to describe the data set as a whole or one particular aspect. This is essentially a choice about whether to report the total number of themes or focus on one (or a small group of) theme(s). As such, it represents a quantity versus quality consideration. We chose to identify and analyze all themes relevant to social exchanges during visitation. The participants' experiences with social exchange at visitation were extremely nuanced and complex, and we felt all shared experiences should be included.

The third guideline involves determining whether the themes should be identified according to an inductive or deductive approach. Deductive methodologies can be described as a "top down" approach because the analysis is guided by the researcher's interest in a particular theoretical model. In contrast, inductive methodologies are "data driven" because the theme(s) is derived from the data themselves, not for the purpose of testing a theoretical framework. Our research took an inductive approach to analyzing social exchanges. We wanted to allow the families to speak for themselves instead of attempting to fit their narratives into preconceived conceptual or theoretical typologies. How and whether the results reflect theoretical constructs was secondary to providing an accurate portrait of the participants' experiences.

The last guideline involves identifying the "level" of analysis. There are two possible levels of thematic analysis: latent or semantic (Boyatzis, 1998). Latent analysis involves looking beyond the overt content of the data in an attempt to interpret some underlying meaning or construct. Our research was conducted on the semantic level. We wanted to describe the families' experiences as they themselves expressed them and provide an account of their experiences with social exchanges at visitation.

Making these four decisions involves establishing a framework for the subsequent analysis. The next step in the Braun and Clarke (2006) model of thematic content analysis involves following a six-phase analytic procedure. The first phase is to familiarize oneself with the data. The interviews were collected either over the phone or in person. We made notes whenever able about social exchanges referenced by the participants. We also read each interview transcript and noted prominent characteristics of social exchanges in the participants' narratives. These notes served as a foundation for the subsequent phases of analysis.

Phase two begins the coding process. We first extracted all references to helping behavior from the interview transcripts and collected them in a separate file. Using these references, we began to code for certain characteristics of social exchanges - e.g., who was receiving, who was providing, where were they exchanging, what exactly did they exchange, and did they explain why they were exchanging.

Phase three involves reviewing the coded data and identifying patterns, or themes, in the participants' talk about social exchanges at visitation. The coded narratives were carefully reviewed several times until a preliminary set of themes was identified.

Phase four requires reviewing the accuracy and reliability of the identified themes. There are two criteria commonly used in thematic content analysis to establish that patterns are accurate and reliable themes - internal homogeneity and external heterogeneity (Patton, 1990; Braun \& Clarke, 2006). The former refers to the fact that the data collated within each theme should cohere together in a meaningful way. External heterogeneity refers to the relationship between themes. There should be clear and identifiable differences across individual themes. In this sense, then, phase four primarily involved testing the developed themes for construct validity. The data in each theme were read and re-read until it was clear that they formed a coherent pattern. 


\section{TRAHAN \& EVANS}

Phase five requires defining and labeling themes. The definitions and labels should capture its meaning and establish what is unique about each theme. In the current study, the label and definition of each theme was based on its semantic content regarding what it was describing about the participants' experiences with social exchanges at visitation.

Phase six involves generating the report or manuscript. The premise here is to maintain the organization of themes in the report and convey the results in a way that is a rich yet accurate representation of the data. Quotes from interview transcripts were also selected that best illustrate each theme.

\section{RESULTS}

Table 1 provides basic descriptive statistics for the sample.

Table 1: Sample Characteristics $(n=19)$

\begin{tabular}{|c|c|c|c|}
\hline & $f$ & $\bar{x}$ & Range \\
\hline Age & --- & 57 & $36-71$ \\
\hline \multicolumn{4}{|l|}{ Race } \\
\hline African-American & 1 & --- & --- \\
\hline Hispanic & 2 & --- & --- \\
\hline Caucasian & 16 & --- & --- \\
\hline \multicolumn{4}{|l|}{ Education } \\
\hline High school & 2 & --- & --- \\
\hline Some college & 9 & --- & --- \\
\hline College & 5 & --- & --- \\
\hline Post-graduate & 3 & --- & --- \\
\hline \multicolumn{4}{|l|}{ Perceived Social class } \\
\hline Lower & 2 & --- & --- \\
\hline Lower middle & 3 & --- & --- \\
\hline Middle & 11 & --- & --- \\
\hline Upper middle & 2 & --- & --- \\
\hline No answer & 1 & --- & --- \\
\hline Length of incarceration* & --- & 6.2 years & 6 months -26 years \\
\hline Time since release* $(\mathrm{n}=10)$ & --- & 3.7 years & 1 month -13 years \\
\hline Time left on sentence* $(n=19)$ & --- & 9.8 years & 3 years -24 years \\
\hline
\end{tabular}

* At the time of the interview

All told, 19 of the 35 participants discussed social exchanges at visitation with their loved ones. The remaining 16 participants made no reference to helping behavior. Because we could not determine whether they participated in or even observed helping behavior, they were excluded from the analysis. Each of the included participants participated directly in the exchanges they described. Results of the thematic analysis show two major themes, each of which has several subthemes. The two major themes were labeled "visitation" and "helping behavior." Visitation includes descriptions of the participants' experiences visiting their loved ones in prison. The analysis showed that visitation is much more than the "place" where helping 
behavior occurs. The participants' experiences and feelings about visitation create a context that shapes the need for and function of social exchanges. Subthemes of visitation are "inherent qualities," "bureaucratic process," and "officer mistreatment." The theme "helping behavior" includes descriptions of the participants' engagement in social exchanges with other visitors. Subthemes of helping behavior include "why help," "who helps," "help with what," and "reciprocity." These results are described in further detail below, and quotes from participants are provided to illustrate each theme and subtheme.

\section{Visitation}

The participants described helping behavior as a response to and a mechanism to cope with the overwhelming experience of visiting their loved ones in prison. They routinely used words such as anxiety, stress, intimidation, and fear to describe their experiences with visitation. To be sure, the participants described the actual visit - i.e., the time they spent interacting with their loved ones - in positive terms. Virtually everything else about the experience, however, from the prison environment to the process of visitation and their experiences with correctional officers were sources of stress and anxiety. The results of our thematic analysis show three subthemes or interrelated sources of stress and anxiety at visitation that set the stage for helping behavior.

First, some of the anxiety they experienced was a result of the inherent qualities of having their loved one incarcerated and having to visit them in prison. These inherent qualities included entering a prison environment, seeing their loved one as an inmate, and having to leave them behind after the visit. Consider the following quote from a participant recalling the first time she visited her son in prison.

I was very anxious going, and because I was there and because I had to do this and because of the presence of the gates and the wires and, you know, the building and everything.

One other inherent quality of visitation the participants described as causing stress and anxiety was when they could not have physical contact with their loved ones. Not all the participants were prohibited at all times from having physical contact with their loved ones. When they were, however, it was a singular source of stress, anxiety, and emotional pain. According to one participant, "At first we couldn't do face to face with him and that was hard, that I couldn't touch him and hug him for a while. That to me was a nightmare. It just killed me."

The second subtheme of visitation that caused the participants stress and anxiety and ultimately established the context for helping behavior was the bureaucratic process they had to navigate to see their loved ones and the bureaucratic rules that governed their visits. The participants described a litany of rules at each prison that regulated where they could go, what they could do, how long they could do it, and what they could bring. They explained that it was difficult to fully know all the rules that governed visitation, especially when they first started visiting their loved ones. They felt that the prison system exacerbated their anxiety by failing to provide some kind of adequate resource or reference that explained what the rules were and how to best abide by them. 


\section{TRAHAN \& EVANS}

[We were] very nervous, very...trying to make sure [we] do everything right. Not really knowing how early you need to get there to get into visit. Not knowing what you should wear, what you can and can't wear. Not knowing that you can't wear an underwire bra. Not knowing that you can't wear certain colors in certain prisons. Everything is a learning experience and they don't do anything to try and help you beforehand.

Even as they became more experienced, however, their anxiety about the bureaucratic process did not necessarily subside. Participants described their loved one's "catching chain," i.e., being transferred to new prisons, and that the rules were often different from one prison to the next. Their anxiety over the process and rules also persisted because, based on their accounts, the rules were enforced arbitrarily. They explained that some prisons were stricter in enforcing visitation rules, whereas some were relatively lax. The result of these ongoing experiences is a persistent lack of confidence in their ability to traverse the visitation process without violating some rule. Regardless of their efforts to conform to the rules, they felt that there was always a real possibility that they would be turned away and not get to visit their loved ones because they might accidentally violate a rule. This was described as a tremendous and persistent source of stress, anxiety, and intimidation.

The fear that if you didn't have it right, you wouldn't be able to get in and see him. We tried to play by the rules every time and for the most part it was okay. But, there were times that we felt...not guilty but, is my hair....do I have the right belt on or should I take it off? We felt intimidated by the pressure of what we could and couldn't do. We would go to different units and that kind of stuff and sometimes the rules would change at the different units that he was incarcerated at.

The third subtheme to emerge regarding sources of stress, intimidation, and anxiety related to the correctional officers (COs) who oversaw visitation. COs evoked the strongest contemptuous language compared to the other two subthemes. Many of the participants seemed to understand the need for strict rules in visitation and that the inherent sources of their stress and anxiety were inevitable. The stress and anxiety-inducing actions of the COs were conversely seen as unreasonable and even malevolent. Participants often described feeling anxious and intimidated by not knowing what to expect from different COs. Some COs, they explained, treated them well while others treated them inhumanely. Moreover, some COs were strict and authoritarian in enforcing the rules, whereas others were relatively calm. A participant explained, "So, kind of horrible way of treating people and depending on who was at the door, whether they treated you like a human being or a piece of dirt once you got in there."

The participants often stated that the COs' mistreatment exacerbated the other sources of stress and anxiety. That is, the inherent sources of stress and the anxiety experienced from the bureaucratic process were made worse by the behavior of some COs.

All the fences and all the gates you have to walk through, and the guards are rude most of them are, not all of them. But they kind of look at you like, how dare you're here and you're only here because your son's horrible and you know all that kind of stuff. 
The participants often described the COs as being rude or unkind. These participants felt that COs should have made a better effort to be professional and understanding of the situation. Because they failed to do so, the COs made a bad situation unnecessarily worse. There was a segment of the sample, however, who felt that the COs' behavior was more than unkind. Some COs were described as intentionally sadistic. These participants described them as engaging in abhorrent behavior in a conscious attempt to torment them.

A security officer comes back and she goes, "we're canceling visitation tonight. Y'all can all go home." She turned around and walked out of the room. And so literally, if you had a job you would have taken off time from work, come up there, waited there for three-and-a-half or four hours only to be told to go home for no reason. Then, she comes back after we're gathering our stuff and started to walk out and, really a lot of grumbling, really, the whole room amplified in talking, and she comes back and she says, "Ha, ha. I'm just kidding. I've got to entertain myself somehow."

The results of our thematic content analysis show that these features - the inherent qualities of visiting loved ones in prison, the bureaucratic process, and mistreatment by the guards - established a context that shaped the need for and function of helping behavior. The following section describes the major features of the participants' helping behavior and how it was shaped by the experiences with visitation described above.

\section{Helping Behavior}

The overwhelming features of visitation shaped why visitors helped each other, who gave and received help, and what they helped each other with. The results of the analysis show four subthemes in the participants' narratives about helping behavior at visitation. The first three subthemes relate to the characteristics of social exchange stated just above - "why help," "who helps," and "help with what." The fourth subtheme - "reciprocity" - describes a temporal process whereby receivers of resources become providers over time.

The results show that the overwhelming experience of visitation is why visitors engage in helping behavior with each other. That is, all visitors confront an intimidating environment of state power, governed by a long list of seemingly arbitrary rules they struggle to follow, and the behavior of the COs exacerbated the visitors' tension and anxiety. The participants' comments indicate that they feel similarly situated in this experience, which creates an "us versus them" mentality. They developed a shared sense of empathy and a tendency to identify with one another. Helping behavior became a way of establishing a sense of community and togetherness. In this vein, helping behavior was described as a necessary or natural response to overwhelming conditions.

It was a bond made with people during that period of time. You were all in that together you were all in the same situation it didn't matter. Race, economic, nothing; you were all wanting to get into to see your love ones. So [helping each other] was just the normal thing we did. You knew it was you against them that was 


\section{TRAHAN \& EVANS}

the reality of it. The overwhelming experience of visitation also shapes who provides and receives help.

Receivers are generally inexperienced visitors who are relatively new to visitation. Providers are generally people who have more experience with visitation. In this dynamic, new visitors were much more anxious and overwhelmed by visitation relative to their more experienced counterparts. They were more unaware of the rules that governed visitation and the formal and informal processes that must be traversed in order to interact with their loved ones. The more experienced visitors were savvier and less intimidated. The experienced visitors explained that novice visitors were easy to identify, and the former offered resources in an effort to mitigate the stress and anxiety that the latter experienced. As one participant said, "You could always tell the new ones. Everyone knew about the quarters except the new people." Another participant elaborated:

Oh absolutely. You could see if someone was new. When you stand in those lines, waiting to get in, sometimes it could be hours, and you learn to just share with people. You learn to say things like, "is this your first time"? "Yeah." "Okay, when you come back in, you can't do this." You tend to give them the rules and regulations. They'll give you basic rules but we'll tell you the rules that really work and don't work.

The third subtheme of helping behavior related to resources that the visitors exchanged. The results of our analysis showed that helping behavior involved exchanges of socioemotional and minor material and practical support. The material support that was provided mostly involved providing money for vending machines to new visitors. As the participants described to us, visitors are allowed to bring money to buy snacks from the vending machine in the visitation room, and snacks are very important to the inmates. As with all things, however, bringing quarters was governed by various rules that are not clearly explained to people prior to visitation. These rules were commonly (a) visitors could bring only quarters, not paper money or other coins; (b) visitors could bring no more than fifteen to twenty dollars in quarters; and (c) quarters must be in a clear plastic bag. More experienced visitors would often give some of the quarters they brought to newer visitors who did not know they could bring money or had violated one of these rules.

And we would take about $\$ 15.00$ worth of quarters so we would have a snack with him and we would buy him whatever he wanted, a soda. There were times when we would go and we would see somebody that was new and was there for their first time and they we're sitting there with their loved one and didn't have a quarter to their name because they didn't know. They didn't know that they could bring in quarters so we would always go and just lay down like $\$ 3.00$ worth of quarters on the table and say, "for your visit." You could always tell the new ones. Everyone knew about the quarters except the new people. You know, first visits, they don't tell you a lot.

Although no single material good was involved in helping behavior as much as quarters, various other material goods were exchanged among visitors. Participants discussed sharing extra chairs, 
jackets in the winter, and neutral color shirts with other visitors. The quote below came from a participant who explained she kept wireless bras in her trunk to share with other visitors. Bras with underwire are prohibited at visitation.

I keep wireless sports bras in my trunk. They call it my "bra-ministry." I looked at the website very carefully and, you know, read it like four times and highlighted it just because I'm anal and a teacher, and even I forgot once and I had to go out in the parking lot with a pair of clippers and take the stupid wires out of my bra. So, I always keep some in the trunk that are new, that I just get from Wal-Mart and if somebody gets stuck then I give them one. Just tell them to keep it.

Helping behavior also included advice and socioemotional support. Advice commonly involved savvier, more experienced visitors helping newer visitors traverse the process and rules of visitation. More experienced visitors would explain to novices where they must go, what they could do, and what they should expect from the COs. As previously discussed, participants regularly described to us that they did not know the rules in the beginning and that the system does little-to-nothing to educate them. Experienced visitors took it upon themselves to help teach newer visitors.

Everything is a learning experience and they don't do anything to try and help you beforehand. I actually created a Facebook page and tried to update people at various prisons as we went and learned. I would put knowledge out there for people so they would know, so they would know what they had to do in order to pass, to get in and visit their loved one. Helping them understand what they could and couldn't wear. Helping them know what documents they needed to bring. Helping them know that they need to be on a visit list. Just a host of things that you have to know that no one tells you about.

Much of the helping behavior can be described as socioemotional support. This was a clear response to the overwhelming and anxiety-inducing experience of visitation. Participants shared stories of them giving and receiving encouragement from more experienced visitors. The socioemotional support served to lessen the stress and anxiety they experienced. They were told that "things get better," that they had to be strong for their loved ones, and that they were not alone.

You learn to become family with other families that come because you are all in the same boat. I remember several times just going to the restroom, just having to hold another woman because it was her first visit or something bad happened and she had to tell him bad news and just holding women in the bathroom. We would just hold each other and cry because nobody understood our pain. They just don't make it easy for you and they degrade you and they talk bad about you and they humiliate you because they treat you like they treat him inside there.

The last subtheme of helping behavior was reciprocity. Participants often described an informal system of "paying it back" wherein helpees become helpers over time. More experienced visitors explained that seeing new people at visitation conjured memories of what it 


\section{TRAHAN \& EVANS}

felt like to be in this place and process in the beginning. They described helping new people in part because they remembered receiving help when they were new.

Some places you go you have to stand in line before you get checked in, and when you see people that are standing there with their purse or they don't have their quarters in a baggy, you know, you try to let them know because I know people did that for us.

In sum, a total of 19 of 35 participants described being involved in helping behavior while visiting their loved ones in prison. Visitation and their experiences therein established a context that created the need for and helped shape the form and function of helping behavior. In this context, the participants formed a sense of community wherein older, more experienced visitors helped newer visitors by exchanging a variety of resources. This sense of community and resource exchange was reciprocal in that helpees became helpers as they gained more knowledge and experience.

\section{DISCUSSION}

This study explored family members' and significant others' experiences during visitation with their incarcerated loved ones. Respondents recounted negative experiences during prison visitations with incarcerated loved ones. It was difficult to see their loved one locked in a secure facility. However, the process of learning the rules and navigating the bureaucracy of previsitation security was a particularly overwhelming and intimidating experience for respondents. The long list of seemingly arbitrarily written and implied rules and perceived rude and illtreatment by COs only made visits more challenging and stressful. Visitors perceived judgment from COs, and the treatment they experienced made them feel subhuman. Navigating the difficulties of visitation, many individuals who were previously strangers came together through the shared experience of visiting an incarcerated family member and formed a community focused on helping one another. They offered one another practical advice, material goods and money, and emotional support and communication.

The findings reported here show that visitors help one another in a way consistent with social exchange theory. Respondents offered help to neophytes and/or received assistance from others who had more experience visiting a prison. Exchanges of help among visitors to prisons reproduced itself as new visitors attempted to learn the process for entering a secure facility and spending meaningful time with incarcerated loved ones. Reciprocity is fundamental to social exchange theory in that it ensures that exchanges continue over time. Indeed, the findings reported here mirror the results of research on social exchanges in various communities, including knowledge sharing on the internet (Jinyang, 2015), volunteerism at work (Jones, 2010), and resident support for tourism in their areas (Nunkoo \& Ramkissoon, 2012). All these communities engage in reciprocal models of social exchange. Individuals who at one point received help from others eventually "paid it back" to newer visitors. Whether there was an expectation of reciprocity, sympathy for new visitors, or a sense of obligation to help others learn the process of visitation, reciprocal exchanges contributed to the development of a communal relationship among visitors to prisons. Communal relationships expanded and reproduced social exchanges with each new visitor learning how to traverse prison visitation and receiving help 
from more experienced visitors. Experienced visitors helped newer visitors, and as new visitors became more familiar with the process over time, they transitioned to the role of helpers.

Visitors are not always in a position to offer help to others because they may lack the resources or knowledge that would benefit others. Helpers must have a surplus of resources (information, money) to offer assistance and receivers must have a deficit and a need for these resources. Our finding that givers have a surplus of knowledge from their learned experience visiting prisons or extra money or material goods needed for visitation to help others supports Meeker's (1971) assertion that continued social exchange depends on those with surplus resources contributing to the larger community of those in need.

Our findings reflect the importance of trust in social exchange relationships. Visitors relied on each other for emotional support and tangible resources, and many felt that they could only trust other visitors because of their similar experiences visiting an incarcerated loved one, their mutual feelings of denigration at the hands of COs when attempting to enter the facility, and the intimidation that many experienced during the process of visitation. Trust is essential to forming a sense of community in and around social exchanges (Buchan, Croson, \& Dawes, 2002). Among our respondents, trust facilitated the exchange of information and resources and contributed to the building of communal relationships among visitors.

Psychological research has posited a range of explanations for the motivation to help others. Motivations for helping are categorized into three primary categories: learning how and why to help others, social and personal norms regarding helping behavior, and the emotional arousal that people feel when helping others (Dovidio, Piliavin, Schroeder \& Penner, 2017). Respondents in this study demonstrated components of all three motivations. As recipients of help, they learned from their helpers when and how to provide help. Helpers were, in part, influenced by norms of "us versus them" in regards to correctional officers; because COs were unwilling to help them, visitors band together to help one another. Offering help to others reflects empathy and concern for others (Davis, Hall \& Meyer, 2003). After helping others, they experienced positive emotions and felt good about themselves. People who receive positive feedback after helping feel better about themselves for having provided help (Dovidio \& Penner, 2003). Feelings of gratitude explain the reciprocal helping exchanges exhibited during prison visitation. People who experience the emotion of gratitude are more likely to display prosocial or helping behavior to others, including strangers (Bartlett \& DeSteno, 2006).

Social exchange between visitors is almost necessary for first-timer visitors to learn the intricacies of the process. First-timers face a number of obstacles as they attempt to visit a secure facility. Prior to their first visit, they have to arrange to be on a visitor list, and many facilities require them to fill out a visitor's application and submit to a background check. There is a dress code, restrictions on items allowed inside the facility, and visitors are searched before entering the jail or prison. Visitation hours are limited, so that delays in the pre-visitation process will reduce the time that visitors can spend with their incarcerated loved ones. Rules vary across facilities but are extensive, often detailed, and not well-publicized for visitors to learn and prepare for them in advance. Learning facility rules for visitations can be a frustrating experience that unites others to understand and navigate them collectively. Exchanges of help among visitors with greater and lesser levels of experience in this learning process can empower novice visitors to have more control over their visits.

Visits between inmates and loved ones are beneficial to both parties for several reasons. Visits contribute to maintaining relationships, ameliorating the prison environment, and preparing individuals for reentry. Prison managers allow visitation in prison in part to improve 


\section{TRAHAN \& EVANS}

the demeanor of inmates and facilitate rehabilitation through relationship building with family members and loved ones (Maruna \& Toch, 2005). The more positive the visitation experience, the greater the benefits. Constructive interactions between COs and visitors can diminish perceptions of threat and demonstrate that COs are helpful and serve a vital purpose inside jails and prisons (Casey-Acevedo \& Bakken, 2002). This finding is particularly relevant to first-time visitors and children visiting their parents in a secure facility because first impressions have enduring consequences that can affect encounters during subsequent visits. Receiving visitors may lessen the negative effects of being socially isolated (Cochran \& Mears, 2008). Visitation can also have long-term effects, as pleasant contacts during repeated visitations facilitate postrelease adjustment for the inmate and family members and reduce recidivism (Schafer, 1994; De Claire \& Dixon, 2017).

The purpose of thematic content analysis is to identify similar experiences across multiple respondents. However, several differences between the participants and their experiences became apparent during the analysis that might help the reader interpret the results. First, helping behavior during visitation mainly involves family members demonstrating agency and resilience in the face of adversity. Some participants in the analysis were more resilient than others. Confronted with the ominous experience of visiting their loved ones in prison, some participants were extremely intimidated, overwhelmed, and scared. Others expressed anger and frustration. All of these various emotional reactions lent to engaging in helping behavior, but there were clear personality differences involved. Second, the participants' experiences with visitation, in general, were somewhat varied. Some participants included in the analysis described persistent feelings of anxiety and emotional pain at having to visit their loved ones in prison. Others described a mix of emotions. They explained that the process required to gain access to their loved ones was a source of anxiety, but the time they spent together was a positive, exciting, emotional experience. Again, all of these participants engaged in helping behavior, and, importantly, they all cared deeply for their loved ones. We encountered no instances of extreme hostility and resentment toward their incarcerated loved ones. However, the way participants related to their experiences varied somewhat. These issues - the differences between people and their experiences visiting family in prison - were beyond the scope of the current study but should be explored in future research.

Despite the number of benefits associated with positive visitation experiences, visitations to prisons do not occur frequently. A study of 247 family members of incarcerated persons found that half of intimate partners and over 70 percent of blood relatives never visited their incarcerated family members (Naser \& Visher, 2006). Other studies have found that more than 50 percent of inmates do not have any visitors or have no visitors in the year leading up to their release (Glaze \& Maruschak, 2008; Bales \& Mears, 2008). There are many reasons for not visiting an incarcerated family member. Distance, cost, time conflicts, nature of the relationship, and barriers associated with facility visitation rules could all play some role in discouraging visits.

Many of the participants in the current study were recruited through groups that provide support to family members of incarcerated persons, such as Texas Inmate Families Association. One important facet of this sampling strategy that is pertinent to the current study is participation in these groups likely fostered helping behavior and shaped respondents' attitudes about helping behavior. In a way, involvement in support groups mirrors helping behavior during visitation. Support groups offer socioemotional and practical support to inmates' families. It is also likely that there is a reciprocal process involved in support group participation. Family members who 
are new to the experiences of having a loved one incarcerated may receive help. As they become more experienced, family members may transition to providing support in support groups. Sampling through support groups may have biased the results, however. People who participate in support groups may be more likely to engage in helping behavior than the general population of families of the incarcerated. They also may be more likely to offer substantial and material support, such as money for vending machines and clothing. Including a disproportionately large number of participants from support groups may thus have inflated the findings. The following section discusses other limitations of the current study.

\section{Limitations and Future Research}

The findings of the current study are limited in several respects. The sample size is somewhat small, and results may be biased. This, of course, is not atypical of qualitative research, but it is worth noting that the generalizability of the findings cannot be assumed. A larger sample size might yield different results that are more accurately representative of people's experiences visiting loved ones in prison. The participants almost exclusively lived and visited prisons in Texas and New York. It is possible that prison systems in other states manage visitation in different ways that are not so detrimental to the emotional and material well-being of families. Some of the participants' experiences were driven by the rules and processes of visitation. These rules and processes are governed mainly at the state level. Thus, we cannot determine whether the results reported here are representative of people's experiences visiting loved ones in other states.

Moreover, the financial cost and emotional toll that traveling to prisons to visit loved ones may be higher in Texas, given the geographic size of the state, than in other states. Also, we did not ask the participants about the offenses that their loved ones were convicted of. Some of the participants volunteered that information, but we have no way to determine if the sample is overrepresentative of certain types of offenses. This could bias the results because people convicted of certain offenses and their families may have different experiences with visitation and interactions with correctional officers. The sample is also over representative of parents. Of the 35 total participants, 23 were parents of an incarcerated loved one. It seems certain that parents would have different experiences with visitation and social exchanges than other family members. Thus, the results reported here are skewed toward the experiences parents have visiting their children in prison.

One other limitation of the current study is that we were unable to contextualize the findings in the visitation environments. It is plausible that various characteristics of the prisons, such as security levels or the configuration of visitation rooms, influence helping behavior among visitors. We were unable to include such variables in our analysis for several reasons. First, we did not design the study at the outset to analyze helping behavior during visitation. The study was designed to explore the collateral effects of incarceration on families. Helping behavior emerged during our talk with the respondents. Second, many of our respondents visited their loved ones' in several different facilities through the duration of their incarceration. They often visited loved ones in county jails prior to their conviction. After their conviction, loved ones were routinely transferred to different facilities around their respective states, something the respondents referred to as "catching chain." Moreover, some loved ones in our sample were convicted of federal offenses and were transferred to different facilities around the country. This 


\section{TRAHAN \& EVANS}

would have made any attempt to capture detailed information about the institutional context of visitation, and analyze how those contexts shaped helping behavior, practically problematic.

Future research should attempt to gather data from a potentially more generalizable sample. Whether this would involve a larger sample size, participants from diverse geographic areas, and whose loved ones were convicted of various types of offenses or different family members and significant others should be based on the interests of the researchers and it certainly resource dependent. However, any measure to increase the external validity of results would be valuable to understanding the general experiences of people visiting loved ones in prison and, ultimately, how to improve their experiences. Future research might also incorporate both qualitative and quantitative data and conduct mixed-methods analyses. Doing so would allow researchers to identify causal relationships and provide a richer, more detailed account of family members and significant others' experiences with visitation specifically and having a loved one in prison generally.

\section{Policy Recommendations}

Visitation between inmates and their family members and loved ones should be encouraged, and facility superintendents and correctional officers should make visitations as painless and positive as possible. Sturges (2002) argues that correctional officers overseeing visitations should be trained from a human services rather than a security-oriented perspective so they can deal with the trauma of prison visitation and address other issues that may arise. This training could be provided for all guards overseeing visitation, or a specialized few. One advantage that training a specialized few in human services could provide is that these officers could leave most if not all security-oriented issues to other officers and focus instead on facilitating visitation among families. The quality of care afforded to families could be considerable if it were the sole or primary focus of a few officers.

One major source of anxiety experienced by the participants that could be quite easily addressed was not knowing the rules that govern visitation and a concomitant fear that they might not be allowed to see their loved ones if they unwittingly violated a rule. One simple remedy is that facility administrators could create an online and printed version of a visitor guide that explains the rules and procedures for visiting prisons. Correctional officers should discuss the most important rules, especially with first-time visitors, to ensure that visitation proceeds smoothly. Facility staff trained in counseling or social work could also be available during visitations for social support. To be sure, there is little that can be realistically done about the inherent qualities of visiting a loved one in prison. However, these and any other seemingly minor policy changes could have a significant and positive impact on the families and significant others who come to prisons to visit loved ones.

\section{REFERENCES}

Arditti, J. A. (2003). Locked doors and glass walls: Family visiting at a local jail. Journal of Loss \& Trauma, 8(2), 115-138.

Arditti, J. (2005). Families and incarceration: An ecological approach. Families in Society: The Journal of Contemporary Social Services, 86(2), 251-260. 
Arditti, J. A. (2012). Parental incarceration and the family: Psychological and social effects of imprisonment on children, parents, and caregivers. New York: NYU Press.

Bales, W. D., \& Mears, D. P. (2008). Inmate social ties and the transition to society: Does visitation reduce recidivism? Journal of Research in Crime and Delinquency, 45(3), 287321.

Bartlett, M. Y., \& DeSteno, D. (2006). Gratitude and prosocial behavior: Helping when it costs you. Psychological science, 17(4), 319-325.

Blau, P. M. (1964). Exchange and power in social life. New York: John Wiley.

Boudin, C., Stutz, T., \& Littman, A. (2013). Prison visitation policies: A fifty-state survey. Yale Law and Policy Review, 32, 149.

Buchan, N. R., Croson, R. T., \& Dawes, R. M. (2002). Swift neighbors and persistent strangers: A cross-cultural investigation of trust and reciprocity in social exchange. American Journal of Sociology, 108(1), 168-206.

Casey-Acevedo, K., \& Bakken, T. (2002). Visiting women in prison: Who visits and who cares? Journal of Offender Rehabilitation, 34(3), 67-83.

Christian, J. (2005). Riding the bus: Barriers to prison visitation and family management strategies. Journal of Contemporary Criminal Justice, 21(1), 31-48.

Christian, J., Mellow, J., \& Thomas, S. (2006). Social and economic implications of family connections to prisoners. Journal of Criminal Justice, 34, 443-452.

Clark, M. S., \& Mills, J. (1979). Interpersonal attraction in exchange and communal relationships. Journal of Personality and Social Psychology, 37(1), 12-24.

Clark, V. A., \& Duwe, G. (2017). Distance matters: Examining the factors that impact prisoner visitation in Minnesota. Criminal Justice and Behavior, 44(2), 184-204.

Cochran, J. C. (2012). The ties that bind or the ties that break: Examining the relationship between visitation and prisoner misconduct. Journal of Criminal Justice, 40(5), 433-440.

Cochran, J. C., \& Mears, D. P. (2013). Social isolation and inmate behavior: A conceptual framework for theorizing prison visitation and guiding and assessing research. Journal of Criminal Justice, 41(4), 252-261.

Comfort, M. L. (2003). In the tube at San Quentin: The "secondary prisonization" of women visiting inmates. Journal of Contemporary Ethnography, 32(1), 77-107.

Cropanzano, R., \& Mitchell, M. S. (2005). Social exchange theory: An interdisciplinary review. Journal of Management, 31(6), 874-900. 


\section{TRAHAN \& EVANS}

Davis, M. H., Hall, J. A., \& Meyer, M. (2003). The first year: Influences on the satisfaction, involvement, and persistence of new community volunteers. Personality and Social Psychology Bulletin, 29(2), 248-260.

De Claire, K., \& Dixon, L. (2017). The effects of prison visits from family members on prisoners' well-being, prison rule breaking, and recidivism: A review of research since 1991. Trauma, Violence, \& Abuse, 18(2), 185-199.

Digard, L., diZerega, M., Yaroni A., \& Rinaldi J. (2016). A new role for technology? Implementing video visitation in prison. New York, NY: Vera Institute of Justice. Retrieved October 14, 2017 from https://www.vera.org/publications/video-visitation-inprison

Dovidio, J. F., \& Penner, L. A. (2001). Helping and altruism. In Fletcher, G. J. O. \& Clark, M. S. (Eds.), Blackwell handbook of social psychology: Interpersonal processes (pp. 162-195). Malden, MA: Blackwell Publishers.

Dovidio, J. F., Piliavin, J. A., Schroeder, D. A., \& Penner, L. A. (2017). The social psychology of prosocial behavior. New York: Psychology Press.

Duwe, G., \& Clark, V. (2013). Blessed be the social tie that binds: The effects of prison visitation on offender recidivism. Criminal Justice Policy Review, 24(3), 271-296.

Emerson, R. M. (1976). Social exchange theory. Annual Review of Sociology, 2(1), 335-362.

Foa, U. G., \& Foa, E. B. (1980). Resource theory: Interpersonal behavior as exchange. In K. J.

Gergen \& M. S. Greenberg \& R. H. Willis (Eds.), Social exchange: Advances in theory and research. New York: Plenum.

Gächter, S., \& Fehr, E. (1999). Collective action as a social exchange. Journal of Economic Behavior \& Organization, 39(4), 341-369.

Glaze, L. E., \& Maruschake, L. M. (2008). Parents in prison and their minor children. Washington, DC: U.S. Department of Justice, Office of Justice Programs.

Jinyang, L. (2015). Knowledge sharing in virtual communities: A social exchange theory perspective. Journal of Industrial Engineering and Management 8(1), 170-183.

Johnston, D. (1995). Parent-child visitation in the jail or prison. In K. Gabel \& D. Johnston (Eds.), Children of incarcerated parents (pp. 135-143). New York: Lexington. 
Jones, D.A. (2010). Does serving the community also serve the company? Using organizational identification and social exchange theories to understand employee responses to a volunteerism programme. Journal of Occupational and Organizational Psychology, 83, 857-878.

Klopton, K. L. \& East, K. K. (2008). “Are There Other Kids Like Me?” Children With a Parent in Prison. Early Childhood Education Journal, 36(2), 195-198.

La Vigne, N. G., Naser, R. L., Brooks, L. E., \& Castro, J. L. (2005). Examining the effect of incarceration and in-prison family contact on prisoners' family relationships. Journal of Contemporary Criminal Justice, 21(4), 314-335.

Maruna, S., \& Toch, H. (2005). The impact of imprisonment on the desistance process. In

Mears, D. P., Cochran, J. C., Siennick, S. E., \& Bales, W. D. (2012). Prison visitation and recidivism. Justice Quarterly, 29(6), 888-918.

Meeker, B. F. (1971). Decisions and exchange. American Sociological Review, 36, 485-495.

Molm, L. D., Whitham, M. M., \& Melamed, D. (2012). Forms of exchange and integrative bonds: Effects of history and embeddedness. American Sociological Review, 77(1), 141165.

Naser, R. L., \& Visher, C. A. (2006). Family members' experiences with incarceration and reentry. Western Criminology Review, 7(2), 20-31.

Nunkoo, R. \& Ramkissoon, H. (2012). Power, trust, social exchange and community support. Annals of Tourism Research, 39(2), 997-1023.

Sabel, C. F. (1993). Studied trust: Building new forms of cooperation in a volatile economy. Human Relations, 46(9), 1133-1170.

Sack, W. H. \& Seidler, J. (1978). Should children visit their parents in prison? Law and Human Behavior, 2(3), 261-266.

Schafer, N. E. (1994). Exploring the link between visits and parole success: A survey of prison visitors. International Journal of Offender Therapy and Comparative Criminology, 38(1), 17-32.

Schirmer, S., Nellis, A., \& Mauer, M. (2009). Incarcerated parents and their children: Trends 1991-2007. Washington, DC: The Sentencing Project.

Siennick, S. E., Mears, D. P., \& Bales, W. D. (2013). Here and gone: Anticipation and separation effects of prison visits on inmate infractions. Journal of Research in Crime and Delinquency, 50(3), 417-444. 


\section{TRAHAN \& EVANS}

Sturges, J. E. (2002). Visitation at county jails: Potential policy implications. Criminal Justice Policy Review, 13, 32-45.

Tewksbury, R., \& DeMichele, M. (2005). Going to prison: A prison visitation program. The Prison Journal, 85(3), 292-310.

Travis, J. \& Visher, C. (Eds.) Prisoner reentry and crime in America (pp. 139-178). New York: Cambridge University Press.

Wagner, P., \& Rabuy, B. (2017). Mass incarceration: The whole pie 2016. Prison policy Initiative. Northamption, MA: Author. Retrieved March 10, 2019 from http://www.antoniocasella.eu/nume/Wagner_Rabuy 14mar17.pdf

Adam Trahan is an Associate Professor in the Department of Criminal Justice at the University of North Texas. He received his Ph.D. in Criminal Justice from Indiana University. His research interests include capital punishment and punitiveness, criminological theory, diversity issues, and public opinion.

Douglas Evans is an Associate Professor of Criminal Justice at Fairleigh Dickinson University and a Project Director at the Research and Evaluation Center, John Jay College of Criminal Justice. His research focuses on criminal stigmatization, barriers to reentry for the formerly incarcerated, the effects of incarceration on families, and education programs in prisons. $\mathrm{He}$ received his Ph.D. in Criminal Justice from Indiana University. 